CASE REPORT

I. Craven

U.J. Patel

A. Gibson

S.C. Coley

\section{Symptomatic Perianeurysmal Edema Following Bare Platinum Embolization of a Small Unruptured Cerebral Aneurysm}

\begin{abstract}
SUMmARY: There is considerable interest in the development of symptomatic inflammatory reactions following coil embolization of cerebral aneurysms. Patients have experienced a range of adverse events, usually after treatment of moderately large aneurysms with modified "bioactive" coils. More recently, it has been recognized that adverse inflammatory reactions can be associated with the use of "nonbioactive" coils, and we present a case of symptomatic perianeurysmal edema after treatment of a small unruptured aneurysm with bare platinum coils.
\end{abstract}

$F$ ollowing embolization of aneurysms with conventional bare platinum coils, there is a relatively high rate of angiographic recurrence. Despite the currently observed low rates of delayed bleeding, there has been considerable effort to improve long-term angiographic stability by using a variety of modified "bioactive" coils. Use of these coils has, however, been associated with adverse events, such as hydrocephalus, aseptic meningitis, and local inflammatory reactions. Although the use of these products may be associated with a higher incidence of adverse clinical events, it is also possible to see identical inflammatory reactions with bare platinum coils, as we describe in this report.

\section{Case Report}

A 51-year-old right-handed woman presenting with left-sided sensorineural deafness was found to have a small incidental left middle cerebral artery (MCA) aneurysm on MR imaging. Diagnostic conventional angiography confirmed the presence of a 7-mm aneurysm pointing superiorly and laterally from the proximal bifurcation of the left MCA (Fig 1). After detailed consultation, the patient requested active endovascular treatment and was randomized to bare platinum coils in the Cerecyte Coil Trial. With the patient under general anesthesia, 6 bare platinum coils (Micrus Endovascular, San Jose, Calif) were placed into the aneurysm. A remodelling balloon was not used, and tightly packing the aneurysm without repeated prolapse of coils into the parent vessel proved difficult. As a result, there was suboptimal packing of the aneurysm neck. The patient awoke with no neurologic deficit and was discharged home within 48 hours.

Twenty days after treatment, the patient presented to her general practitioner following 2 nocturnal seizures (tonic-clonic) and further daytime complex partial seizures. After the administration of carbamazepine, the events ceased and the patient did not seek a neurologic consultation for a further 8 weeks. MR imaging at this time (approximately 3 months after embolization) showed new ill-defined increased T2 signal intensity surrounding the aneurysm with contiguous extension into the external capsule and temporal strut, but no hydrocephalus (Fig $2 A-C$ ). Steroids were not prescribed because the patient was symptom-free on anticonvulsant therapy. A check diag-

Received March 5, 2009; accepted after revision March 25

From the Departments of Neuroradiology (I.C., S.C.C.), Neurosurgery (U.J.P.), and Neurology (A.G.), Royal Hallamshire Hospital, Sheffield, UK.

Please address correspondence to S.C. Coley, MD, Consultant Neuroradiologist, Department of Neuroradiology, Royal Hallamshire Hospital, Glossop Rd, Sheffield S10 2JF, United Kingdom; e-mail: stuart.coley@sth.nhs.uk

DOI 10.3174/ajnr.A1643

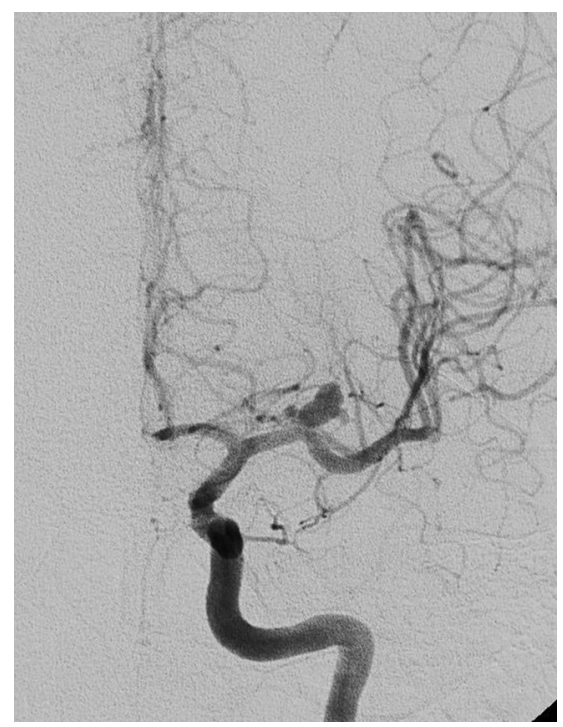

Fig 1. Conventional angiography shows a 7-mm aneurysm arising from the proximal bifurcation of the left MCA.

nostic angiogram at 6 months showed persisting occlusion of the aneurysm fundus with a small stable neck remnant (Fig 3).

Further MR imaging was performed at $3 \mathrm{~T}$ approximately 12 months after treatment. During this period, the patient remained symptom-free and the imaging showed near-total resolution of the perianeurysmal edema (Fig $4 A,-B$ ).

\section{Discussion}

Adverse inflammatory reactions have been described following coil embolization of cerebral aneurysms and may manifest in a variety of clinical ways. These include headache, lethargy, meningism, blindness, confusion, and impaired cognition. ${ }^{1-15}$ MR imaging has been performed in some instances and has variably demonstrated hydrocephalus, aneurysm enhancement, perianeurysmal edema, and perianeurysmal enhancement. ${ }^{2,3,7,9-11}$ Observation of such events has coincided with the increasing use of modified "bioactive" coils, and a causal link has been suggested.

Perianeurysmal edema is not a new phenomenon and has been described with both treated and untreated cerebral aneurysms. The latter are usually large or partially thrombosed lesions, often embedded in the substance of the brain. ${ }^{7}$ Following coil embolization, certain patients have developed de novo edema, whereas treatment has also been associated with 

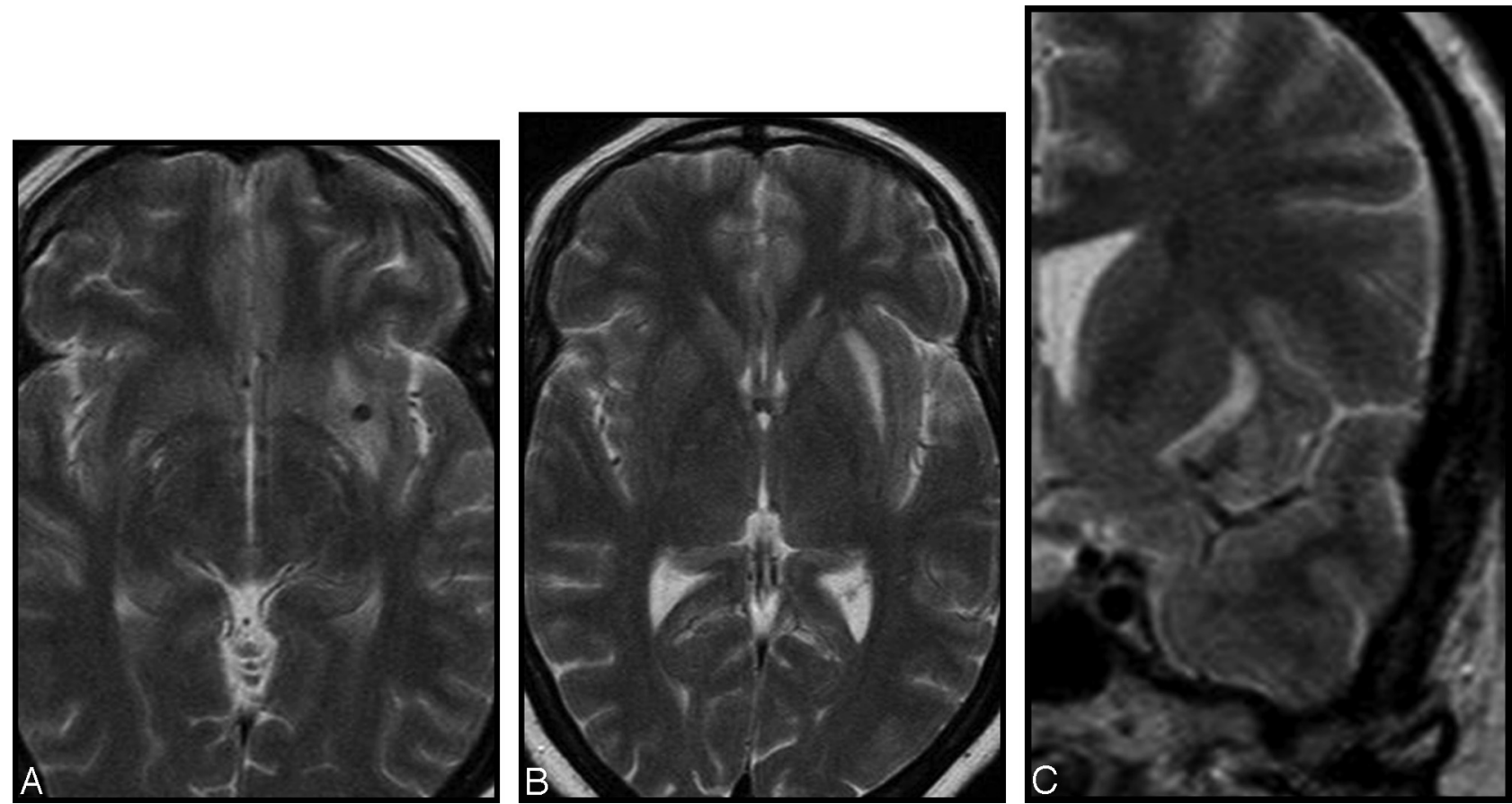

Fig 2. T2-weighted images show high signal intensity surrounding the aneurysm.

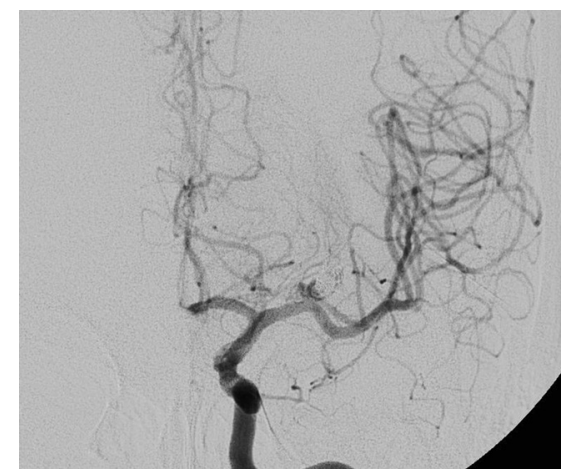

Fig 3. Conventional angiography shows subtotal occlusion of the aneurysm with a small stable neck remnant. a reduction or resolution of the brain edema in others. ${ }^{12}$ The mechanism by which edema develops around an aneurysm is unclear, and various interrelated factors have been postulated. These include intraluminal thrombosis, aneurysm pulsatility, intramural hemorrhage, wall inflammation, and cytokine release. ${ }^{2,12}$ Some patients respond to steroid therapy, a feature that supports an inflammatory etiology, as does the observation of increased white cells and protein in the CSF of certain patients ${ }^{4}$; however, complete symptomatic improvement is not always guaranteed. . $^{3,4,9,13}$

Postmortem histologic studies have revealed an inflammatory infiltrate within the wall of embolized aneurysms, ${ }^{16}$ and this is likely to have a correlate in the form of wall enhancement on gadolinium-enhanced MR imaging studies. ${ }^{7}$ Partly as
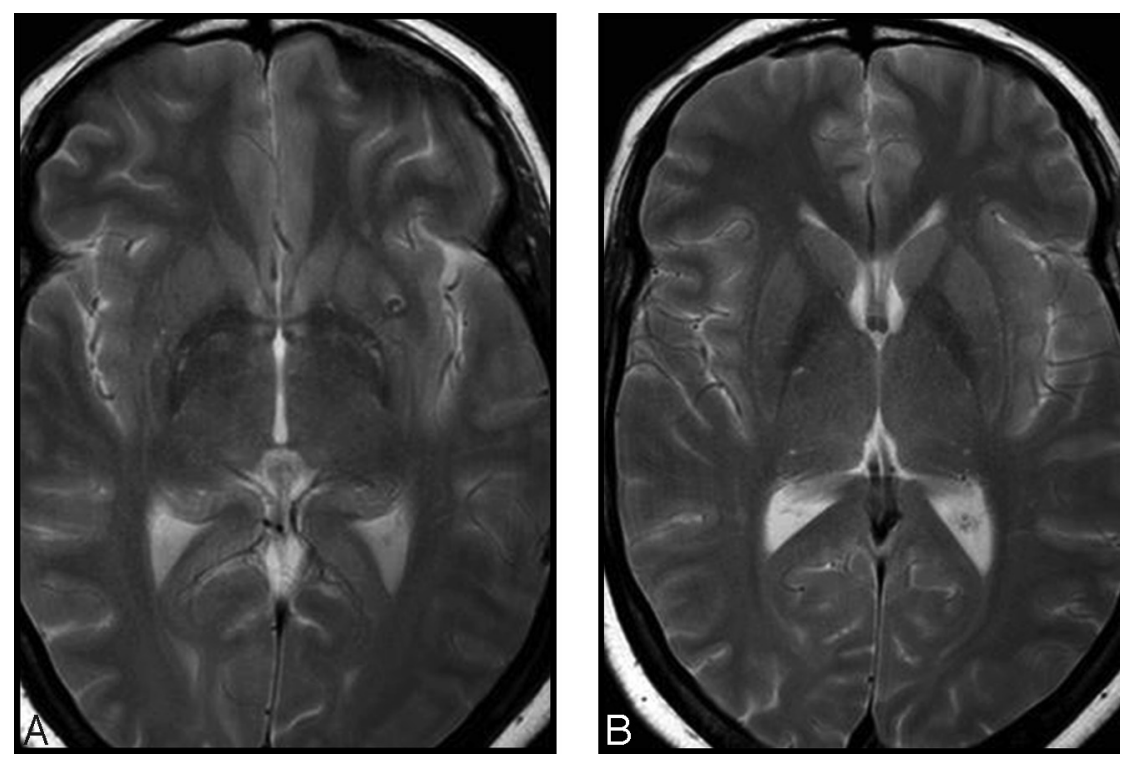

Fig 4. T2-weighted images at 12 months show near-complete resolution of the perianeurysmal edema. 
a result of these observations, there is increasing emphasis on the significance of inflammation within the aneurysm wall and its relationship with the surrounding environment. A recent study has noted that enhancement is greater and persists for longer in large aneurysms, but it can also be observed in asymptomatic patients, including those treated with bare platinum coils. ${ }^{7}$ In this series of patients treated with different coil types, the authors also observed cases of perianeurysmal edema and hydrocephalus, each following the use of hydrogelcoated coils.

The case we describe is interesting in that a significant clinical event (seizure) occurred following treatment of a relatively small aneurysm $(7 \mathrm{~mm})$ with bare platinum coils. Most other radiologic reports of perianeurysmal edema have occurred in larger aneurysms, usually, but not exclusively, with the use of modified coils. It is becoming increasingly apparent that adverse inflammatory reactions, such as perianeurysmal edema are not confined to just 1 coil type and are also observed with bare platinum coils as well as in untreated patients. ${ }^{3,9}$ Only by close surveillance of patients treated with modified coils and by rigorous reporting of adverse events will we understand whether the incidence of inflammatory complications is increased, as many believe, by the use of modified platinum coils.

\section{References}

1. Meyers PM, Lavine SD, Fitzsimmons BF, et al. Chemical meningitis after cerebral aneurysm treatment using two second-generation aneurysm coils: report of two cases. Neurosurgery. 2004;55:1222

2. Stracke CP, Krings T, Möller-Hartmann W, et al. Severe inflammatory reaction of the optic system after endovascular treatment of a supraophthalmic aneurysm with bioactive coils. AJNR Am J Neuroradiol 2007;28:1401-02
3. Schmidt GW, Oster SF, Golnik KC, et al. Isolated progressive visual loss after coiling of paraclinoid aneurysms. AJNR Am J Neuroradiol 2007;28:1882-89

4. Im S-H, Han MH, Kwon BJ, et al. Aseptic meningitis after embolization of cerebral aneurysms using hydrogel-coated coils: report of three cases. AJNR Am J Neuroradiol 2007;28:511-12

5. White PM, Lewis SC, Nahserc H, et al. HydroCoil Endovascular Aneurysm Occlusion and Packing Study (HELPS Trial): procedural safety and operatorassessed efficacy results. AJNR Am J Neuroradiol 2008;29:217-23. Epub 2008 Jan 9

6. Cloft HJ. HydroCoil for Endovascular Aneurysm Occlusion (HEAL) study: periprocedural results. AJNR Am J Neuroradiol 2006;27:289-92

7. Fanning NF, Willinsky RA, TerBrugge KG. Wall enhancement, edema and hydrocephalus after endovascular coil occlusion of intradural cerebral aneurysms. J Neurosurg 2008;108:1074-86

8. Kang HS, Han MH, Lee TH, et al. Embolization of intracranial aneurysms with hydrogel-coated coils: result of a Korean multicenter trial. Neurosurgery 2007;61:51-58

9. White JB, Cloft HJ, Kallmes DF. But did you use HydroCoil? Perianeurysmal edema and hydrocephalus with bare platinum coils. AJNR Am J Neuroradiol 2008;29:299-30. Epub 2007 Nov 16

10. Bendszus M, Solymosi L. Cerecyte coils in the treatment of intracranial aneurysms: a preliminary clinical study. AJNR Am J Neuroradiol 2006;27:2053-57

11. Mitha AP, Wong JH, Lu JQ, et al. Communicating hydrocephalus after endovascular coiling of unruptured aneurysms: report of 2 cases. J Neurosurg 2008; 108:1241-44

12. Horie N, Kitagawa N, Morikawa M, et al. Progressive perianeurysmal edema induced after endovascular coil embolization: report of three cases and review of the literature. J Neurosurg 2007;106:916-20

13. Pickett GE, Laitt RD, Herwadkar A, et al. Visual pathway compromise after HydroCoil treatment of large ophthalmic aneurysms. Neurosurgery 2007;61: E873-74

14. Berenstein A, Song JK, Niimi Y, et al. Treatment of cerebral aneurysms with hydrogel-coated platinum coils (HydroCoil): early single-center experience. AJNR Am J Neuroradiol 2008;29:1067-70. Epub 2008 Apr 3.

15. Deshaies EM, Adamo MA, Boulos AS. A prospective single-center analysis of the safety and efficacy of the HydroCoil embolization system for the treatment of intracranial aneurysms. J Neurosurg 2007;106:226-33

16. Bavinzski G, Killer M, Gruber A, et al. Treatment of basilar artery bifurcation aneurysms by using Guglielmi detachable coils: a 6-year experience. J Neurosurg 1999;90:843-52 